\title{
ADRENAL MALIGNANT MELANOMA MASQUERADING AS A PHEOCHROMOCYTOMA
}

Maria E Barmpari ${ }^{1}$, Christos Savvidis ${ }^{1}$, Anastasia D Dede ${ }^{1}$, Haridimos Markogiannakis², Dimitrios Giannopoulos ${ }^{3}$, Christina Dikoglou ${ }^{3}$, Sofia Malaktari-Skarantavou ${ }^{1}$

${ }^{1}$ Department of Endocrinology and Metabolism, Hippokration Hospital, Athens, Greece, ${ }^{2}$ Department of Endocrine Surgery, First Department of Propaedeutic Surgery, Hippokration Hospital, Medical School, University of Athens, Athens, Greece, ${ }^{3}$ Department of Pathology, Hippokration Hospital, Athens, Greece

\section{Introduction}

- Pheochromocytomas represent tumors arising from the adrenal medulla. Their principal characteristic is the secretion of catecholamines (epinephrine, norepinephrine, dopamine).

- The adrenals are a common metastatic site of lung, breast, ovarian and skin cancer. Malignant melanoma originates principally from the skin and rarely from other tissues, like eye's choroid tissue, esophagus, colon, while sporadic cases of primary adrenal melanoma have also been described.

\section{Case Description}

- A 61- year- old male was referred for evaluation of a $5 \times 5 \mathrm{~cm}$, well defined, firm mass in the right supraclavicular region and another $88,5 \mathrm{~mm}$ inhomogeneous lesion in the left adrenal.

- He had a medical history of total thyroidectomy with cervical lymph node dissection because of a multifocal papillary and medullary thyroid carcinoma three years before presentation.

- Post- thyroidectomy imaging had been negative as was genetic testing for RET proto- oncogene mutation.

- The patient had no symptoms or signs of catecholamine excess. Apart from the palpable neck mass, the rest of the physical examination was unremarkable.

\section{Laboratory tests (before and after adrenal dissection)}

\begin{tabular}{|l|l|l|l|}
\hline & Before & After & Reference range \\
\hline Calcitonin & $217 \mathrm{pg} / \mathrm{ml}$ & $351 \mathrm{pg} / \mathrm{ml}$ & $(<18)$ \\
\hline Thyroglobulin & $0,26 \mathrm{ng} / \mathrm{mL}$ & & $(<78)$ \\
\hline AntiTg & $<2,2 \mathrm{U} / \mathrm{ml}$ & & $(<20)$ \\
\hline Chromogranin A & $2,2 \mathrm{nmol} / \mathrm{l}$ & & $(<4)$ \\
\hline Neuron Specific Enolase & $79 \mu \mathrm{g} / \mathrm{l}$ & $11,9 \mu \mathrm{g} / \mathrm{l}$ & $(<16)$ \\
\hline 24h urinary catecholamine & $817 \mu \mathrm{g} / 24 \mathrm{~h}$ & $432 \mu \mathrm{g} / 24 \mathrm{~h}$ & $(80-515)$ \\
\hline 24h urinary epinefrine & $8,8 \mu \mathrm{g} / 24 \mathrm{~h}$ & $10,8 \mu \mathrm{gg} / 24 \mathrm{~h}$ & $(4-25)$ \\
\hline 24h urinary norepinefrine & $105,1 \mu \mathrm{mg} / 24 \mathrm{~h}$ & $88,9 \mu \mathrm{gg} / 24 \mathrm{~h}$ & $(20-105)$ \\
\hline 24h urinary dopamine & $703 \mu \mathrm{g} / 24 \mathrm{~h}$ & $332 \mu \mathrm{g} / 24 \mathrm{~h}$ & $(65-400)$ \\
\hline 24h urinary VMA & $6,2 \mathrm{mg} / 24 \mathrm{~h}$ & $3,9 \mathrm{mg} / 24 \mathrm{~h}$ & $(1-11)$ \\
\hline
\end{tabular}

- Dopamine-secreting pheochromocytomas are extremely rare and have been associated with lack of the characteristic symptoms indicative of catecholamine excess and with greater rates of malignancy.
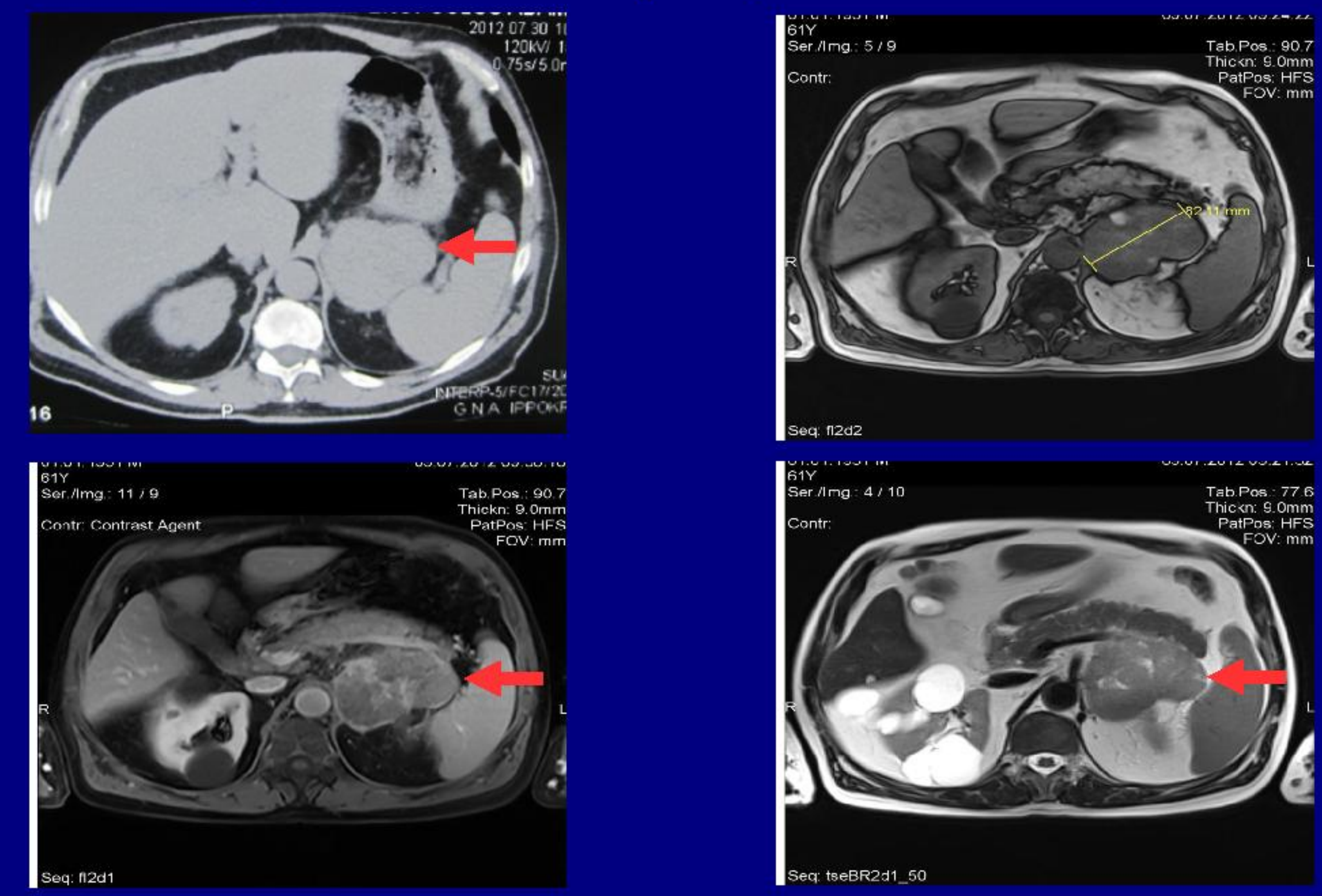

CT (top left): Inhomogeneous solid mass $8,5 \mathrm{~cm}$ in diameter with diffuse hemorrhagic and necrotic areas and increased tracer uptake

MRI: large, solid mass $88,5 \mathrm{~mm}$ in diameter of the left adrenal gland, with inhomogeneous enhancement of the contrast agent and a low diffusion rate.
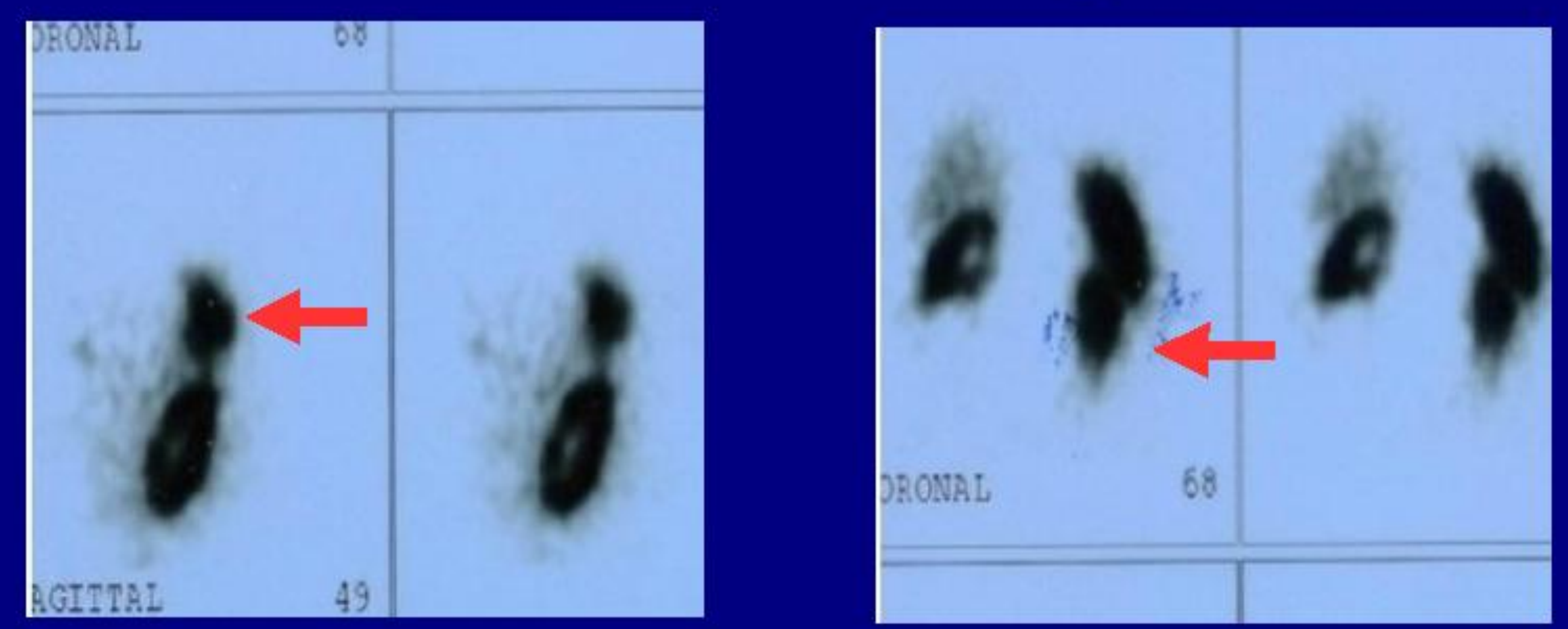

111ln- Pentetreotide (OCTREOSCAN):

- Increased tracer uptake in the left adrenal gland

${ }^{131}$ I- MIBG : negative (not displayed).
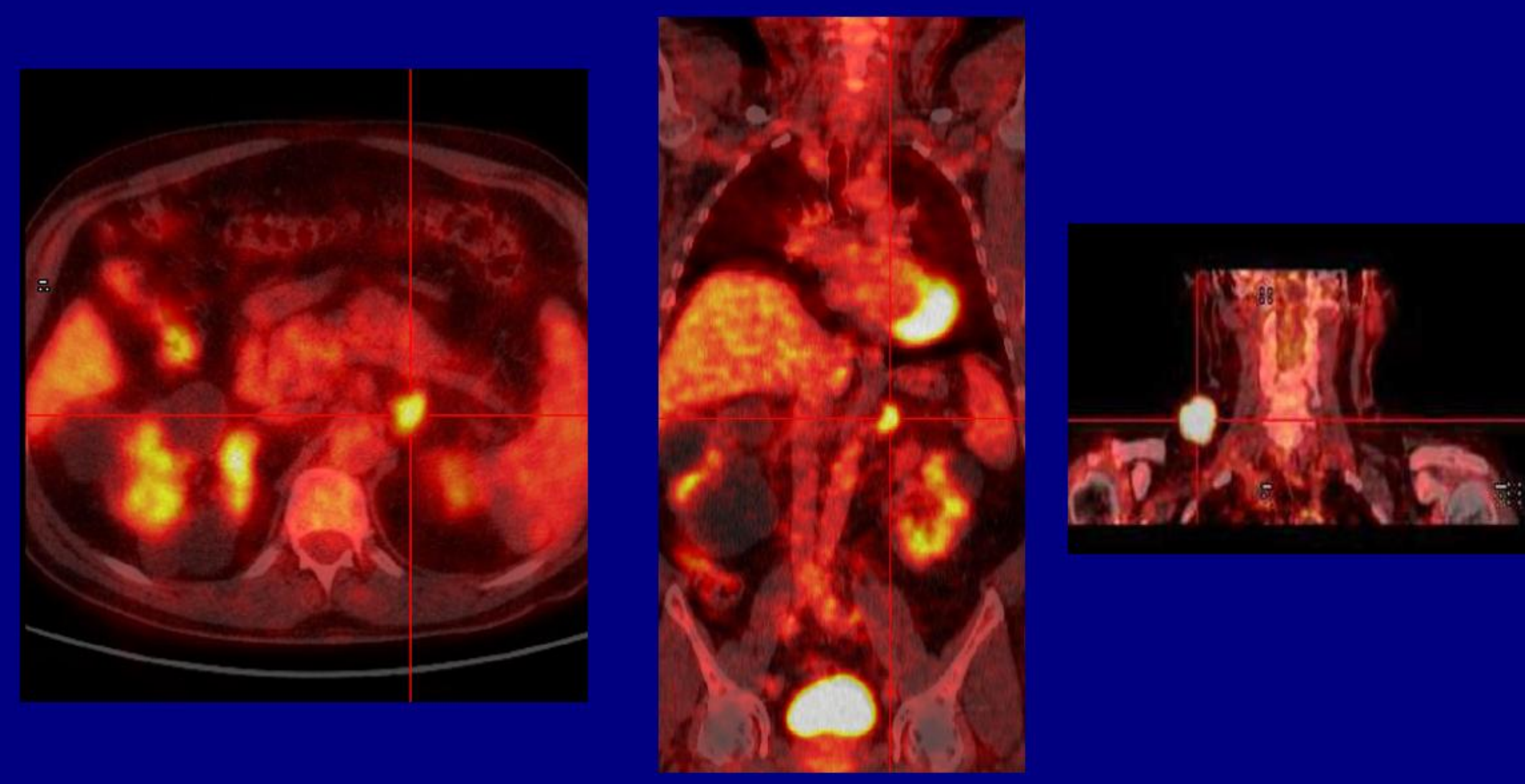

F18- FDG PET/CT 11,5 mCi:

- Left adrenal gland (SUV max: 4,7).

- Right supraclavicular region (SUV max: 10,0).
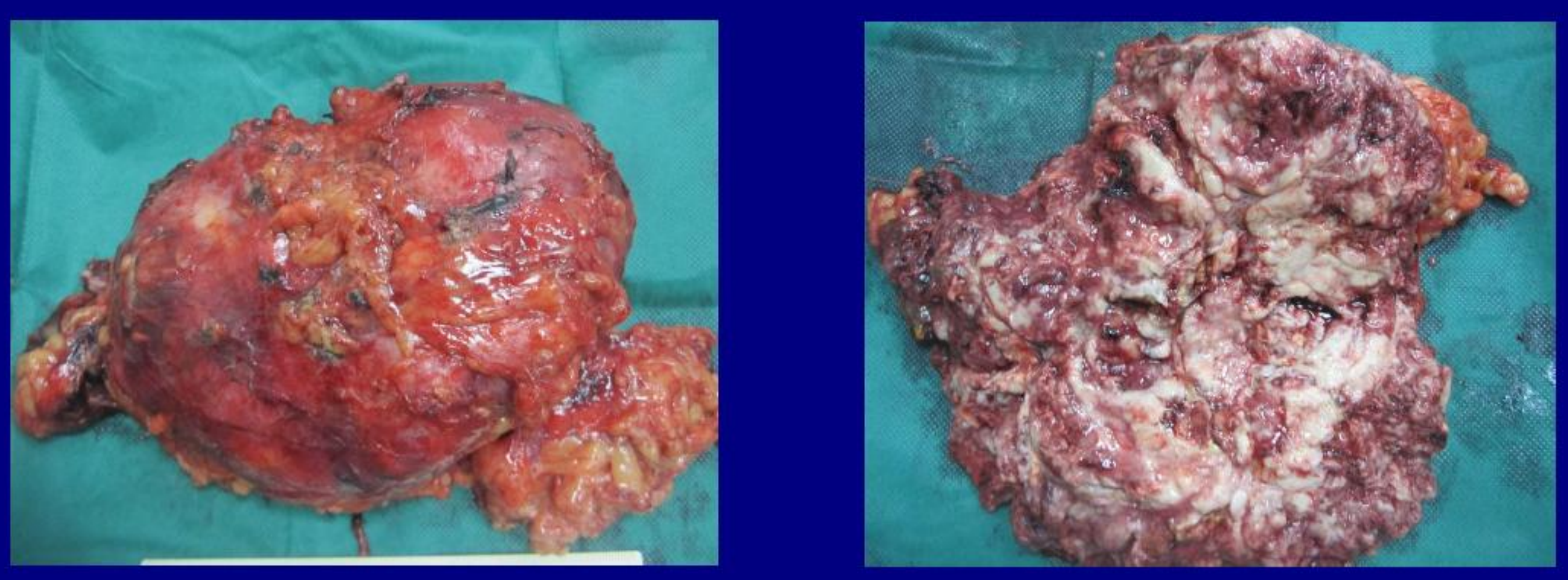

- Tumor $16,5 \times 10,7 \times 10 \mathrm{~cm}$ in diameter which occupies the left adrenal gland.

- No infiltration of the capsule, the surrounding lymph nodes and organs.

- Poorly differentiated malignant neoplasm composed of spindle shaped or epithelioid cells, with eosinophilic cytoplasm, markedly atypical and pleomorphic nuclei with prominent nucleoli, abundant mitoses and areas of necrosis.

. Strong possitivity for immunohistochemical markers S- 100 and Melan- A.

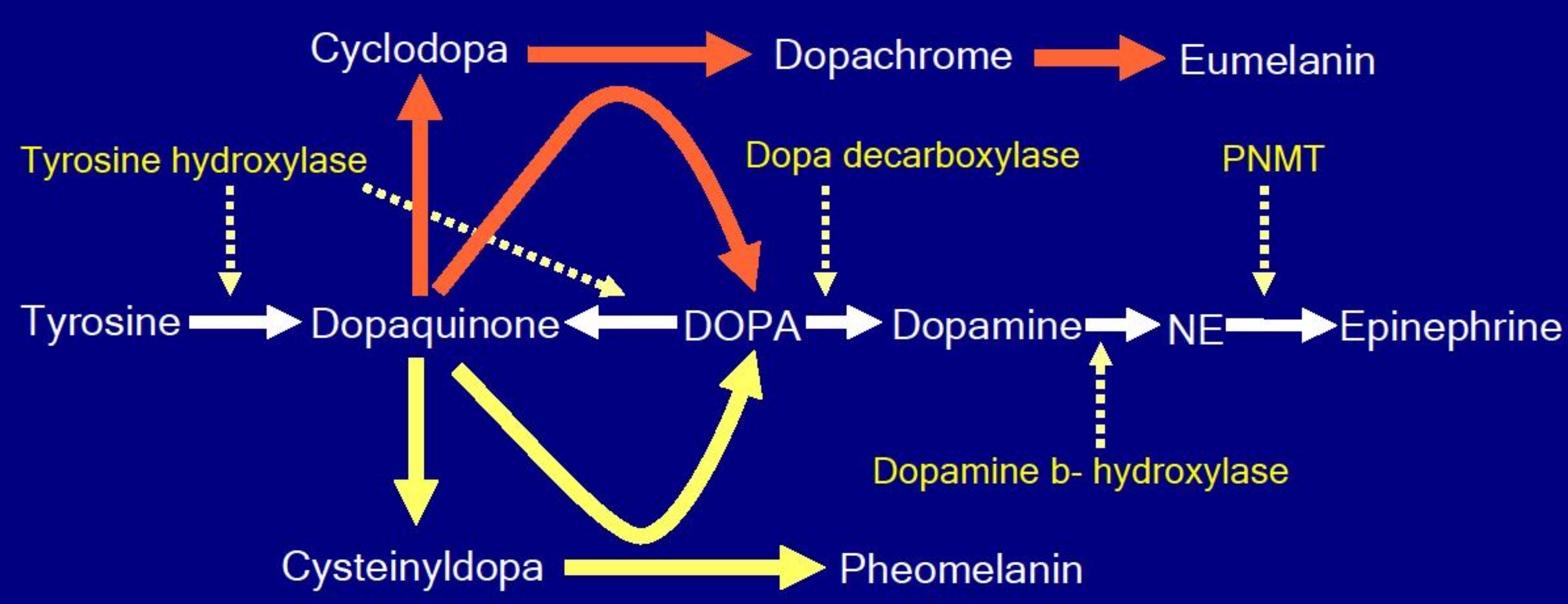

Biosynthetic pathway of melanins and catecholamines:

- In melanoma tissue there is induction of tyrosine hydroxylase leading to production of DOPA and melanins. Activity of DOPA decarboxylase converts part of DOPA to 3,4- dihydroxyphenylethylamine (dopamine, DA).

\section{Conclusions}

This rare case illustrates the difficulties in the differential diagnosis of a dopaminesecreting adrenal mass. Both adrenal melanomas and pheochromocytomas should be considered in the differential diagnosis of an adrenal mass, especially when the primary biochemical finding is an increased urinary dopamine excretion in order to determine the best diagnostic approach to the patient.

\section{References:}

- Poirier É, Thauvette D, Hogue J-C 2013 Management of Exclusively Dopamine-Secreting Abdomina Pheochromocytomas. Journal of the American College of Surgeons 216:340-346

- Kaltsas G, Korbonits M, Heintz E, Mukherjee JJ, Jenkins PJ, Chew SL, Reznek R, Monson JP, Besser GM Foley R, Britton KE, Grossman AB 2001 Comparison of Somatostatin Analog and Meta-lodobenzylguanidine Radionuclides in the Diagnosis and Localization of Advanced Neuroendocrine Tumors. Journal of Clinical

Endocrinology \& Metabolism 86:895-902

- Ito S, Wakamatsu K 2008 Chemistry of Mixed Melanogenesis-Pivotal Roles of Dopaquinone. Photochemistry and Photobiology 84:582-592 